\title{
Polysaccharide-based Biomaterials with Antimicrobial and Antioxidant Properties
}

\author{
Véronique Coma \\ Unité des Sciences du bois et des Biopolymères, \\ UMR 5103 Université Bordeaux1, CNRS, INRA, \\ 351 cours de la Libération, \\ 33405 Talence Cedex, \\ Phone (33) 5 4000-2913 \\ Fax: (33) 5 4000-6439 \\ E-mail:v;coma@us2b.u-bordeaux1.fr
}

\begin{abstract}
Active packaging is one of the responses to the recent food-borne microbial outbreaks and to the consumer's demand for high quality food and for packaging that is more advanced and creative than what is currently offered. Moreover, with the recent increase in ecological awareness associated with the dramatic decrease in fossil resources, research has turned towards the elaboration of more natural materials. This paper provides a short review of biomaterials exhibiting antimicrobial and antioxidant properties for applications in food preservation. The two main concepts of active biopackaging materials are briefly introduced. The different polysaccharides potentially used in packaging materials are then presented associated with a brief overview of research works related to biopackaging, exhibiting notably antimicrobial or antioxidant properties. Finally, future trends such as the release-on-demand of bioactive agents are discussed.
\end{abstract}

Keywords: Polysaccharides, active biomaterials, antimicrobial and antioxidant biopackaging.

\section{Introduction}

Due to the numerous applications of polysaccharides in biomatrices for different applications, only the different polysaccharide utilizations in biopackaging will be developed here.

Packaging is generally used to maintain the quality and extend the shelf life of food products ${ }^{[1-3]}$. Food-borne disease has always topped the list of food safety concerns for most governments around the world ${ }^{[4,5]}$. Bacterial enteric pathogens contribute significantly to these concerns and food-producing animals are seen as one of the major sources for many of these strains, leading to safety problems. Salmonellosis and listeriosis represent respectively 31 and $28 \%$ of total food-related deaths, whereas Campylobacter and Escherichia coli represent 5 and $4.3 \%$ and Staphylococcus aureus only $0.8 \%{ }^{[6,7]}$. Aside from disease-causing bacteria, spoilage microorganisms also lead to significant economic losses ${ }^{[8]}$.

In addition, oxidative reactions are among the main factors reducing the shelf life of perishable foods, affecting all aspects of food quality. Hydrolysis and oxidation are the two basic reactions that cause the deterioration of fats. Lipids undergo auto-oxidative degradation during storage. The presence of metals in fats greatly accelerates the oxidation process. Inactivation of the catalysis effect of these metals can be achieved by the use of a sequestering agent, e.g. citric acid. Moreover, fat oxidation by bacteria can also occur.

To prevent the negative consequences of food contamination and oxidative processes, active packaging materials could help minimize the risk of contamination. Active packaging material is defined as: a type of packaging that changes the condition of the packaging to extend shelf-life or improve safety or sensory properties while maintaining the quality of the food ${ }^{[9]}$.

In order to inhibit the development of pathogen or spoilage micro-organisms, packaging with antimicrobial properties can be used, notably based on the progressive release of edible biocide such as organic acids and their salts, ethanol, bacteriocins, etc. It is important to note that the use of antimicrobial packaging is not meant to be a substitute for good handling practices, but it should enhance the safety of food as an additional impediment to the growth of pathogenic and/or spoilage microorganisms $^{[10]}$. Active packaging, exhibiting antioxidant properties could be very useful to decrease the risk of oxidation processes, particularly by the release of antioxidant compounds ${ }^{[11]}$. Many of the antioxidants present in food have the function of terminating chain reactions. A variety of compounds such as phenols, aromatic amines, and conjugates can function as chainbreaking antioxidants.

Stricter requirements regarding consumer safety are leading towards the development of new approaches and strategies in the food and packaging industry ${ }^{[12]}$. The new Regulation, notably in Europe, will authorize the use of active and intelligent packaging, provided the packaging can be shown to enhance the safety, quality and shelf-life of the packaged foods (new Framework Regulation for Food Contact Materials, 1935/2004/EC) ${ }^{[13]}$.

Renewed interest in food packages based on natural macromolecules in recent years has been due to concerns about the environment, to a decrease in 
fossil resources, and to a need to reduce the amount of disposable packaging materials. It was made applicable in the European community by the directive 94/62/CEE on plastic waste, requiring to find alternative methods of disposal. The technological challenge is the compromise to be found between the stability during the useful life cycle of the material and the degradation expected at the end of the product's life $\mathrm{e}^{[14]}$. Biomass is a naturally abundant source of sustainable biopolymers, and in the last few years, increasing environmental awareness has led to growing interest in the development of green compounds with improved performance. Biopolymer films and coatings, which act as a barrier to external elements (bacteria, moisture, oil, gases, volatile organic compounds...) and, thus, protect the product and extend its shelf-life, are generally made from biological

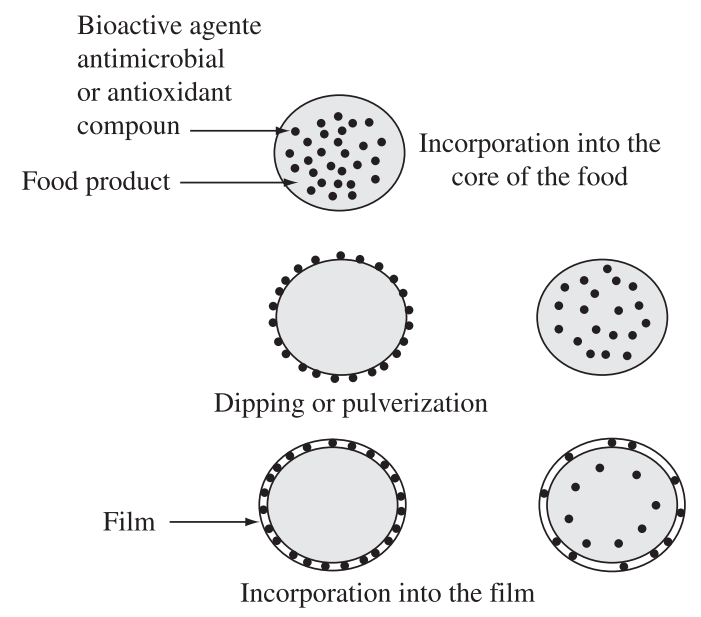

Figure 1. Different incorporation modes of additives in food products (incorporation into the foodstuff, dipping or pulverization, and finally incorporation into a film) and their consequences. The black dots correspond to an active agent (antimicrobial compound or antioxidant). materials such as polysaccharides, proteins, lipids, and derivatives $^{[15-17]}$.

An exciting innovation in active biopackaging is the potential of the controlled release of active agents from packaging materials. Indeed, combining active agents directly into a packaging material could provide several advantages. The system is more efficient than the direct application of the active agent onto selected surfaces, because it slows down the migration of the agents away from the surface, and thus helps to maintain high concentrations where they are needed. Only the necessary amount of active agent would need to be used (Figure 1). Secondly, in most cases, the agent would not be a direct additive to the food product.

The following sections are an overview of active polysaccharide-derived biopackaging. This review begins by focusing on the general considerations of antimicrobial and antioxidant biopackaging. Following this, it surveys the various polysaccharides that can be used for film formulation and their potential as active biomaterials. As a conclusion, directions for future research or development are suggested.

\section{Antimicrobial and Antioxidant Biopackaging}

Two processes to produce antimicrobial or antioxidant biopackaging can be used in food preservation (Figure 2) $^{[18]}$ :

\section{Direct incorporation of the active agent into the biomatrix: elaboration of biocomposites}

This category of materials can release the antimicrobial agents onto the surface upon which antimicrobial action is needed. As for application in Modified Atmosphere Packaging (MAP), the active agent and particularly antimicrobial compounds may either be released through evaporation in the headspace between the food and the material (volatile substances) or migrate onto the surface of the food (non-volatile additives) through diffusion.

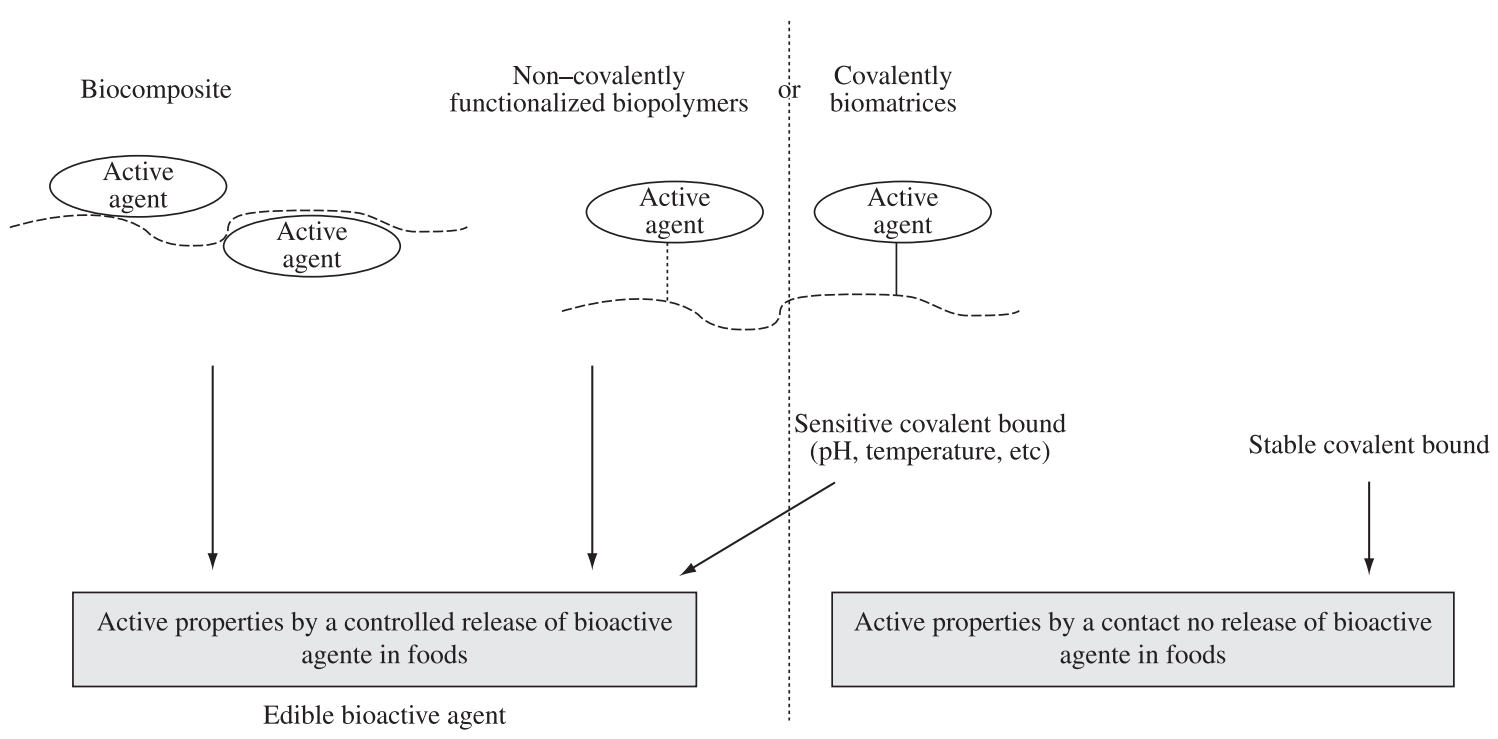

Figure 2. The different processes to produce antimicrobial or antioxidant biopackaging, from biopolymers which are not inherently active. 
The active biomatrix can be used directly as a packaging material or can be coated on a packaging surface and then act as a carrier for the active agent.

\section{Utilization of biopolymers or biomatrices which are chemically modified in order to produce bioactive properties or use inherently active biopolymers exhibiting film-forming properties, such as antimicrobial cationic amino-polysaccharides}

Matrices with bioactive agents chemically bound to the polymer are included in this category and the immobilization of the biocide on the film can be used for bioactive compounds that have not yet obtained authorization for release. For this system, the release of the biocide agent is not required, and can even be prohibited in the case of a potentially toxic active agent. The requirement of a direct contact between the matrix and the body could be a limitation of such a system in some applications. In some cases, e.g. pH-sensitive bond, chemical bonds are created to allow an active agent slow-release system. Functionalization of the surface material with molecules that inhibit microbial colonization or oxidation process allows local availability of active molecules.

Different systems of antimicrobial and antioxidant packaging have already been discussed in previous reviews ${ }^{[19-21]}$ and so, only the potential of polysaccharide-based matrices in active biopackaging will be presented here.

\section{Polysaccharides Applicable for Film Formulation}

Not all the functions of individual polysaccharides are known, but they may act as storage material, structural components and protective substances. Polysaccharides can be found directly in some plants or algae $e . g$. cellulose, starch, alginates, or found in animals e.g. chitin and glycogen. Another source of biopolymers is bacteria and fungi. Micro-organisms can also produce some polysaccharides e.g. cellulose, alginates and other exo-polysaccharides, potentially used in the formulation of biopackaging, due to their gel-forming capacity.

Some of these polysaccharides with film-forming properties are presented here in a non-exhaustive way. Generally, it is well known that polysaccharide-based films, because of their hydrophilic character and because of the make up of the polymer chains, exhibit good gas permeability and low moisture barrier properties, two transfers which play an important role in food preservation.

\section{Plant origin}

\section{Starch}

Starch is a complex carbohydrate, which is potentially soluble in water (Figure 3). It is the major reserve polysaccharide of superior plants. It is used by plants, as a way to store the excess of glucose. It represents an important weight fraction of agricultural raw materials such as cereal (30 to $80 \%$ of the dry mass), tubers (60 to
90\%), and legumes (25 in 50\%). In industry, it is used in the manufacture of adhesives, paper and textiles ${ }^{[14]}$.

The majority of the applications of starch are based on the disappearance of the crystalline fractions, notably obtained by solubilization in solution. In its original native state, starch is a semi-crystalline material, which undergoes a transition -or melting- characterized by a melting point $(\mathrm{Tm})$. Material cristallinity is due to the amylose content and to the linear regions of amylopectine, which exhibit a helix organization due to intermolecular hydrogen bonds between hydroxyl functions ${ }^{[14]}$. The amylopectine branched region constitutes a rather amorphous structure ${ }^{[22]}$. In its transformed state, the mainly amorphous starch goes through a glassy transition characterized by the glass temperature $(\mathrm{Tg})$. The segments of chains within the amorphous phase, thus acquire strong mobility. Between $\mathrm{Tg}$ and $\mathrm{Tm}$, chains may locally recrystallize. These structural modifications occur whatever the thermomechanical past of the material. They have an important effect on the mechanical properties. Thus, the control of Tg is a key point to fix the properties of the material.

In the amorphous state, starch has film-forming properties, which have been well known and described for a very long time. These properties are linked to the average molecular weight, to the amylose/amylopectine ratio and, thus, to the crystalline/amorphous ratio ${ }^{[23]}$. It is also well known that mechanical properties are dependent on the choice of raw material, in particular the content in amylose (Table 1).

An increase in break-strength and elongation percentages are generally observed with an increase in the amylose fraction. Corn starch, which has a high level of amylose, is thus a good candidate for the elaboration of biomaterials. Films are generally transparent and thermoplastic. The presence of controlled water and plasticizer content allows lower glass temperature thus enabling the films to be formed below their

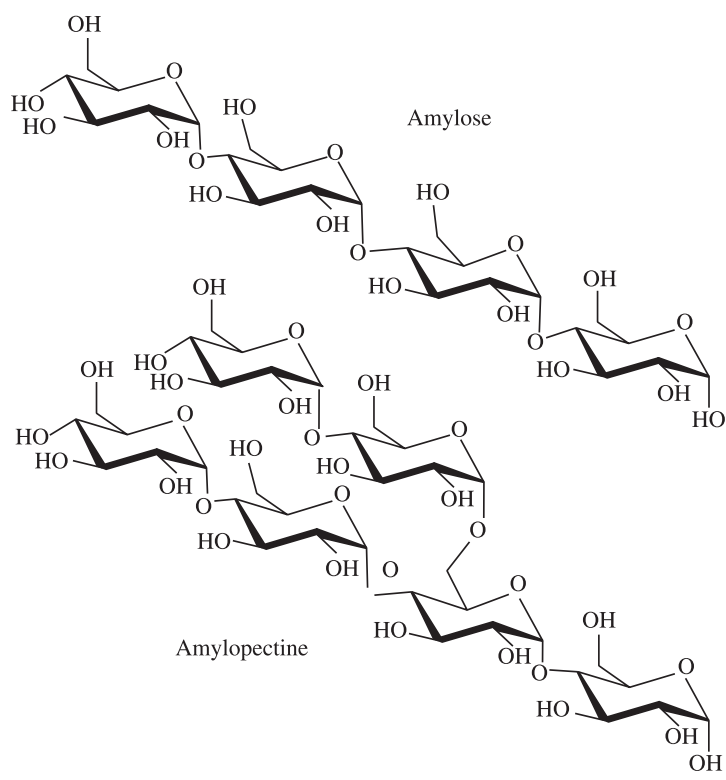

Figure 3. Chemical structure of amylose and amylopectine. 
decomposition temperature ${ }^{[16]}$. The mechanical resistance of starch-based films is generally relatively good, with moderated gas barrier properties. Starch is notably used to elaborate biopackagings with short-term lives because of its moisture sensitivity.

Pyla et al. ${ }^{[25]}$ studied starch-based films, impregnated by tannic acid for the inhibition of Escherichia coli O157:H7 and Listeria monocytogenes, emergent foodborne pathogens. The films had a strong antimicrobial activity on these strains, causing a 2.72$\log$ decrease in L. monocytogenes cells within 48 hours and more than 7-log E. coli O157:H7 cells were killed over the same period. Shen et al. ${ }^{[26]}$ have also prepared antimicrobial biodegradable films with sweet potato starch by incorporating potassium sorbate $\geq 15 \%$ with a significant anti-Escherichia coli effect. These authors have observed that potassium sorbate lowers the tensile strength and elongation at breaking point, and raises the oxygen permeability, water vapor permeability and water solubility.

In order to develop bioactive starch-based film, the association of starch with antimicrobial polymers such as amino-polysaccharides could be an interesting alternative. Vasconez et al. ${ }^{[27]}$ studied antimicrobial edible coating solutions based on blends of tapioca starch-chitosan with or without the addition of potassium sorbate. They showed that the addition of chitosan reduced the water vapor permeability and solubility of starch films. Moreover, the results suggested that antibacterial action depended on the application technique, due to the fact that chitosan is more available in a coating solution than in a film matrix. Interactions between chitosan-starch and/or potassium sorbate affected the film's physical properties and chitosan antimicrobial activity. Shen et al. ${ }^{[26]}$ showed that Staphylococcus aureus could be effectively suppressed by incorporation of chitosan at $\geq 10 \%$ into a starch-based film. The addition of chitosan led to an increase in tensile strength and elongation at breaking point, and an improvement of the oxygen and water vapor barrier, which could be due to hydrogen bonds between chitosan and starch.

In order to produce antioxidant films, some authors ${ }^{[28]}$ successfully incorporated ferulic acid into starch-chitosan blends, and reported intermolecular interactions between the different components. Such ferulic acid-based films result in a reduced formation of lipid peroxide.

\section{Cellulose derivatives}

Cellulose is a native polymer -the most abundant on Earth- with an extended structure involving $\beta-1,4-$ glucosidic linkages between the anhydroglucose

Table 1. Amylose and amylopectine content in natural starches according to Sebti ${ }^{[24]}$

\begin{tabular}{lcc}
\hline & Amylose (\%) & Amylopectine (\%) \\
\hline Potatoes & 23 & 77 \\
Wheat & 20 & 80 \\
Rice & $15-35$ & $65-85$ \\
Corn & 25 & 75 \\
Banana & 17 & 83 \\
\hline
\end{tabular}

repeating units. It is also qualified as a cellobiose polymer (Figure 4).

Three hydroxyl groups with different polarities, secondary $\mathrm{OH}$ at the $\mathrm{C}-2$, secondary $\mathrm{OH}$ at the $\mathrm{C}-3$ and primary $\mathrm{OH}$ at the $\mathrm{C}-6$ position are present, and the formation of strong various intermolecular and intra-molecular hydrogen bonds play an important role in the cohesion and stability of macromolecular chains. Solubility in water decreases with a degree of polymerisation (DP) of more than $6^{[29]}$. Industrially, cotton presents an average DP higher than 500. The paper pulp of Spruce or Beech has a DP of 600-1700. The mechanical resistance (elasticity and strength at break) differs according to the length of fibers (DP). The crystalline structure is due to an helix organization maintained by hydrogen connections. The cellulose is thermostable with a degradation temperature higher than 230. The organization of the cellulose fibers leads to a porous structure.

To elaborate derivatives with film forming properties, cellulose can be esterified or etherified as methyl or ethyl cellulose, hydroxypropyl cellulose, hydroxypropylmethyl cellulose (HPMC), etc.

As for starch-based materials, cellulose-based films are hygroscopic and the properties depend on the relative humidity. For cellulose derivative based films, e.g. methylcellulose, the hydrophilic character varies according to the substitution degree of hydroxyl groups, and the mechanical resistance increases with the decrease in free hydroxyl groups ${ }^{[30]}$. The hygroscopic character also depends on the temperature and on the nature of the substituants ${ }^{[31]}$.

Even if film-forming properties are obtained after chemical modifications, the mechanical properties of cellulose-based films are relatively low compared to polyolefin-based materials (Table 2).

Films made from cellulose derivatives have no inherent inhibitory and antioxidant properties. The majority of the studies are related to the development of biocomposite systems, with a cellulose-based matrix associated with a natural biocide or antioxidant. Growth inhibition of L. monocytogenes and other pathogen strains potentially found in food products has often been studied. Bacteriocins -antibacterial peptides produced by lactic acid bacteria which are generally heat-stable and readily degraded by proteolytic enzymes in the human intestinal tract- have been used in cellulose-based materials by our group ${ }^{[33-37]}$. Antimicrobial biopackagings were also obtained by the incorporation of lysozyme into cellulose acetate films ${ }^{[38]}$ The authors achieved the controlled release of lysozyme by modulating the composition of

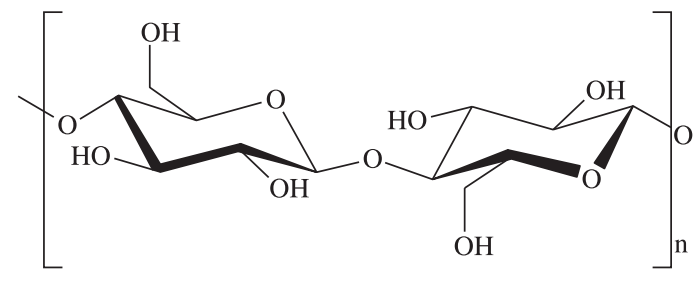

Figure 4. Chemical structure of cellulose. 
the initial casting solution. The highest antimicrobial activity was obtained with the film prepared from 5\% cellulose acetate solution including $1.5 \%$ lysozyme. They showed that the incorporation of lysozyme did not cause significant reductions in tensile strength and elongation at break values except in films prepared with $15 \%$ cellulose acetate.

To prepare biocomposite films from biopolymers with anti-listerial activity and moisture barrier properties, the antimicrobial efficiency of chitosan- HPMC, associated with lipid or chemically modified by crosslinking were also investigated ${ }^{[39]}$. The water vapor transfer rate of HPMC film, $\sim 270 \mathrm{~g} / \mathrm{m}^{2} /$ day.atm ${ }^{-1}$, was improved by incorporating chitosan and was further reduced by $40 \%$ by the addition of stearic acid and/or cross-linking. Chitosan-HPMC-based films, with and without stearic acid, completely inhibited the growth of L. monocytogenes. Nevertheless, a loss of antimicrobial activity after chemical cross-linking modification was observed.

Gemilli et al. ${ }^{[40]}$ studied cellulose acetate films with different morphological features in order to control the release rates of natural antioxidants, L-ascorbic acid and L-tyrosine. Changing the composition of the casting solution to control the degree of asymmetry and pore size of the films and application of either dense or porous sides of the films on food surfaces are key points to obtain desired release rates for the active agents. The highest antioxidant activity in release test solutions was observed with highly porous L-tyrosine containing films. However, these authors observed that when the porosity of the films reduced, the antioxidant activity of L-ascorbic acid released into solution was found to be higher due to trapping of significant amount of L-tyrosine in dense films.

\section{Hemicelluloses}

Interest in hemicelluloses as an alternative to petrochemicals has grown in recent years. Utilizing hemicelluloses from low-value wastewater and agricultural crop residues has many advantages. The term "hemicelluloses" is used for polysaccharides that normally occur in plant tissues together with cellulose, and which can be isolated by extraction either with water or, more frequently, aqueous alkali ${ }^{[41]}$. Hemicelluloses are located primarily in the secondary cell walls, and together with cellulose and lignin, build up the plants.

It is difficult to give the hemicellulose structure (Figure 5), because some of them are linear while others are highly branched. Branched chains are generally short. Hemicellulose sources are corn, wheat, rice, barley, oats, etc. The oses that are implicated in the structure of hemicelluloses are pentoses (xylose and arabinose), hexoses (glucose, galactose, mannose), hexuronic acids (e.g. glucuronic acids), and deoxy-hexoses (e.g. rhamnose, fucose). Hemicelluloses are associated with cellulose and pectic substances and comprise several non-starch, non-cellulosic polysaccharides, including xylans (arabinoxylans and 4-0-methyl-glucuronoxylans), galactomannans, glucomannans, $\beta$-D-glucans (3- and 4-linked), $\beta$-D-glucan-callose (3-linked), and xyloglucans (4-linked $\beta$-D-glucans with attached side chains) ${ }^{[42]}$.

Hemicelluloses are grouped into four classes according to their main types of sugar residues present: (1) xyloglucans (primary cell-walls of all higher plant), (2) xylans (secondary cell-walls of hardwood species and herbaceous plants), (3) mannans (secondary cell-walls of conifers and seeds of Leguminosae) and (4) mixedlinkage $\beta$-glucans $-(1 \rightarrow 3,1 \rightarrow 4)-\beta$-D- glucans (Poales and some ptéridophytes $)^{[43]}$. The main hemicelluloses of hardwood are $\mathrm{O}$-acetylated 4-O-methyl glucuronic acid xylan. Xylans, xyloglucans and galacto-arabinoglucorono-xylan are the main hemicellulose pentosans present in annual plants.

These biopolymers are relatively unexploited commercially, even though they are present in considerable quantities in some plants (Table 3 ).

Gabrielli et al. ${ }^{[45]}$ extracted a polymeric hemicelluloses of relatively high molar mass and narrow molar mass distribution from aspen wood. Hemicelluloses were constructed from a linear $(1 \rightarrow 4)$ - $\beta$-linked D-xylose main chain with a 4-O-methyl- $\alpha-\mathrm{D}$-glucuronic acid substituting the 2-position of approximately every eighth xylose unit. Hemicelluloses were sparingly soluble in

Table 2. Comparison of mechanical and barrier properties of some synthetic and cellulose-based materials according to Cuq et al. ${ }^{[32]}$.

\begin{tabular}{lccc}
\hline & $\begin{array}{c}\text { Strength at break } \\
(\mathbf{M p a})\end{array}$ & $\begin{array}{c}\text { Elongation at break } \\
(\boldsymbol{\%})\end{array}$ & $\begin{array}{c}\text { Water vapor tranfer rate } \\
\left(\mathbf{m o l}_{\mathbf{m}} \mathbf{m} \cdot \mathbf{m}^{-\mathbf{2}} \mathbf{s}^{\mathbf{- 1}} \cdot \mathbf{P a}^{\mathbf{- 1}}\right)\end{array}$ \\
\hline Low density polyethylene & 13 & 500 & 0,05 \\
MethylCellulose & 56 & 18 & 5,23 \\
HydroxyPropylCellulose & 15 & 33 & 2,89 \\
\hline
\end{tabular}

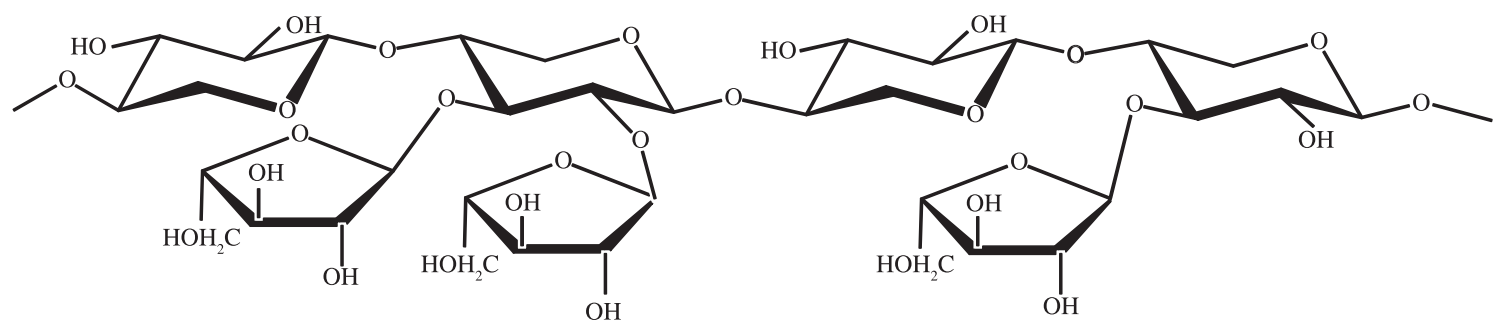

Figure 5. Example of hemicellulose structure: L-arabino-D-xylane according to Ebringerova et al. ${ }^{[44]}$ 
cold water but soluble in hot water. Unfortunately, these authors showed that hemicellulose solutions did not exhibit good film forming properties. Hartman et al. ${ }^{[46]}$ investigated the film-forming ability of the hemicellulose O-acetyl-galacto-glucomannan. To avoid brittleness, a plasticizer was needed, resulting in higher sensitivity to moisture. Interesting oxygen barrier and mechanical strength properties were achieved in a film obtained from a physical blend of hemicelluloses and either alginate or carboxymethylcellulose.

Other authors achieved the elaboration of potential food packaging materials from hemicelluloses ${ }^{[46]}$. It was reported that the oxygen permeability of hemicellulose films was typically comparable to values found for other biopolymer films such as amylose and amylopectin. Hemicelluloses from softwood ${ }^{[47]}$ and hardwood ${ }^{[48]}$ have been shown to have low oxygen permeability and thus have potential as oxygen barrier films.

Gröndah and Gatenholm ${ }^{[47]}$ have shown that barley husk arabinoxylan films had a higher strain at break as compared to aspen glucuronoxylan films at corresponding plasticizer contents. The glucuronoxylan films were semicrystalline, whereas the arabinoxylan films were mainly amorphous. They also observed that both the glucuronoxylan and arabinoxylan films had low oxygen permeability and can thus be used in packaging for oxygen-sensitive products.

To enhance the mechanical properties of xylan as biodegradable material, solutions of xylan could be mixed with solutions of commercially available cellulose esters followed by casting into solid films. Acetylated xylan/cellulose triacetate "blends" could be prepared with mechanical properties comparable to the cellulose triacetate itself up to $25 \mathrm{wt}$. (\%) xylan. ${ }^{[49]}$.

In the review by Hansen and Plackett ${ }^{[45]}$, research on hemicellulose-derived films and coatings showed that the oxygen permeability of hemicellulose films was typically comparable to values found for other biopolymer-based films such as amylose and amylopectin. To decrease the expected water vapor permeability of hemicellulose-based films, chemical modifications have been investigated. However, modified hemicellulose coatings still exhibited water vapor permeabilities several magnitudes higher than those of other polymers currently used for this purpose.

Table 3. Cellulose and hemicellulose content of different plants.

\begin{tabular}{lcc}
\hline \multicolumn{1}{c}{ Biomass } & Cellulose (\%) & Hemicellulose (\%) \\
\hline Softwood & $35-40$ & $25-30$ \\
Hardwood & $45-50$ & $20-25$ \\
Wheat straw & $33-43$ & $20-25$ \\
\hline
\end{tabular}

In the context of bioactive or antioxidant packaging, few studies are based on the use of hemicellulosic resources. It is evident that wood hemicellulose-derivatives have a wide biological activity in plants and also a potential for other biological applications. However, an in-depth study of the use of such compounds in pharmaceutical or health-promoting applications is required. The biological activity of naturally acetylated or deacetylated polymeric structure existing in hemicellulose fractions has recently been a subject of interest ${ }^{[50]}$.

\section{Pectin}

Pectins are acidic and water-soluble hygroscopic polysaccharides, which occur in various natural products, and are found in the primary cell wall in intercellular regions of higher plants. Sources of pectins are traditionally lemon or lime peel (20-30\% of pectin). Pectins from citrus peel can be extracted at $\mathrm{pH}$ 1.5-3 with a temperature of $60-100{ }^{\circ} \mathrm{C}$. After filtration, pectins can be precipitated by the addition of isopropanol.

The key structure for the main pectic polysaccharides, is the presence of linear chain regions comprised of 1-4 linked $\alpha$-D-galactopyranosyluronic acid units (Figure 6).

Relatively few studies have been reported on the use of pectin, either on their own or in combination with other biopolymers as a base packaging material. Low methoxyl pectin requires calcium ion to gel whereas normal pectin produces gels with the presence of acid and sugar. For low methoxyl pectin, the gelification could be due to ionic bonds between calcium ion and carboxylate groups of pectins at a $\mathrm{pH}$ higher than 3.2-4.

Pavlat et al. $^{[52]}$ showed that aqueous solutions of pectin can be cast into clear films but with a low strength and resistance to water. However, recast films immersed into aqueous solutions of multivalent cations became insoluble in water and depending on the ions, became stronger in tension. Tensile strength increased to levels comparable to, or in the case of calcium, copper(II) and zinc, greater than those of some commercial wrapping materials. Kang et al. ${ }^{[53]}$ prepared biodegradable film using citrus pectin, using a combination treatment of gamma irradiation and $\mathrm{CaCl}_{2}$ immersion cross-linking. The tensile strength of the film with $\mathrm{CaCl}_{2}$ was generally higher than that of the non- $\mathrm{CaCl}_{2}$ treatment. Irradiation of the film casting solution at $20 \mathrm{kGy}$ combined with a $5 \% \mathrm{CaCl}_{2}$ immersion resulted in film with improved mechanical properties and biodegradability.

Kang et al. ${ }^{[54]}$ also studied the physicochemical, microbiological and sensorial qualities of cooked pork patty coated with pectin-based material containing green tea leaf extract powder. The numbers of total aerobic bacteria were significantly reduced by the coating treatments. Pectin/Polylactic acid films incorporating

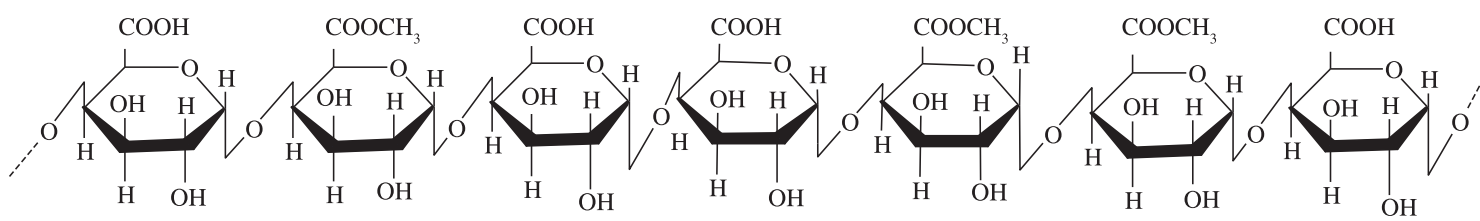

Figure 6. Linear chain region of the pectin structure: homogalacturonan according to Kongruang ${ }^{[51]}$. 
nisin were studied by Jin et al. ${ }^{[55]}$, showing potential for the inhibition of pathogenic L. monocytogenes in orange juice or liquid egg.

\section{Carrageenans and alginates}

Carrageenans is a complex mixture of several polysaccharides. The basic structure of carrageenans is 1- 4-linked- $\alpha$-D-galactopyranose (Figure 7)

Carrageenan gels are thermoreversible. Carrageenan-based coatings have been used to prolong the shelf life of a variety of foods including poultry and fish. Choi et al. ${ }^{[56]}$ elaborated bioactive biopackaging from potassium sorbate incorporated into a K-carrageenan film. They determined the diffusivity of the bioactive agent and investigated the effects of $\mathrm{pH}$ and temperature on its diffusivity.

Alginates derived from seaweed (Phaeophyceae, mainly Laminaria) possess good film-forming properties that make them particularly useful in food packaging applications. They are linear unbranched polymers containing $\beta$-(1->4)-linked D-mannuronic acid and $\alpha$-(1->4)-linked L-guluronic acid residues (Figure 8). Alginates are not random copolymers but, according to the source algae, consist of blocks of similar and strictly alternating residues. Divalent cations (calcium, magnesium, manganese, aluminum, or iron) or acids are used as gelling agents in alginate film formation. Alginate gels are not thermoreversible.

An example of alginate biobased materials with antimicrobial activity can be seen in the work of Marcos et al. ${ }^{[57]}$. These authors studied the capacity of enterocin, produced by Enterococcus faecium, for controlling L. monocytogenes growth in cooked ham. The bacteriocin was included notably in alginate-based biopackaging. A very effective treatment during $6{ }^{\circ} \mathrm{C}$ storage was a vacuum-packaging with alginate films containing $2000 \mathrm{AU} / \mathrm{cm}^{2}$ of enterocins.

Basic repeat structure of carrageenan

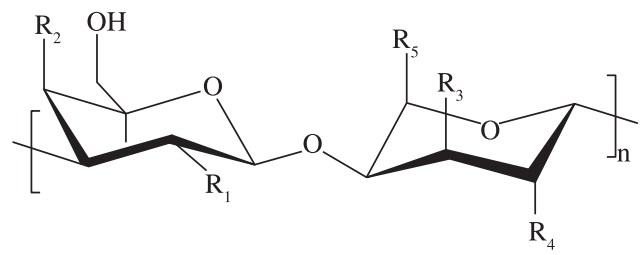

Figure 7. Basic residue of 1- 4-linked- $\alpha$-D-galactopyranose of carageenans.
Oussalah et al. ${ }^{[58]}$, have demonstrated that, after 5 days of storage, alginate-based films containing oregano or cinnamon essential oils were particularly effective against the growth of Salmonella Typhimurium. During the same period, meat inoculated with E. coli O157:H7 and coated with films treated with $2 \% \mathrm{CaCl}_{2}$ had significantly fewer bacteria when oregano-based films were used than when cinnamon- and savory-based films were used.

\section{Animal origin}

\section{Glycogen}

Glycogen is the major reserve polysaccharide of animals and its structure is similar to the structure of amylopectin but more branched.

Very few studies have been reported on the use of glycogen as a base-matrix for biopackaging material. We can quote the work of Izawa et al. ${ }^{[59]}$, which is related to a preparation of glycogen-based polysaccharide gel materials using a phosphorylase-catalyzed chain elongation of glycogen. The resulting solution gradually turned into a hydrogel form, which could be due to the formation of junction zones based on the double helix structure of the elongated amylose chains among the glycogen molecules.

Glycogen, even its film-forming capacities, was not found in the literature as bioactive or antioxidant films for food applications. Its potential utilizations were more frequently mentioned for biomedical biomaterials such as the collagen crosslinker to obtain matrices with defined crosslinking degrees ${ }^{[60]}$.

\section{Chitosan}

Chitosan, (Figure 9), consists of a biopolymer of glucosamine and $\mathrm{N}$-acetylglucosamine units linked by $\beta-1,4$ glycosidic bonds. Today, chitosan is mostly prepared commercially by the alkaline deacetylation of chitin. Chitin, composed of $\beta(1 \rightarrow 4)-\mathrm{N}$-acetyl-Dglucosamine units, is synthesized by a number of living organisms in the lower plant and animal kingdoms, serving many functions where reinforcement and strength are required ${ }^{[61]}$. Chitin is present in nature as ordered microfibrils, and is the major structural component in the exoskeleton of arthropods and the cell walls of fungi and yeast. The main commercial sources of chitin are crab and shrimp shells, which are abundantly supplied as waste products of the seafood industry. Chitin is an extremely insoluble material. More important than chitin is its derivative, chitosan ${ }^{[62]}$.

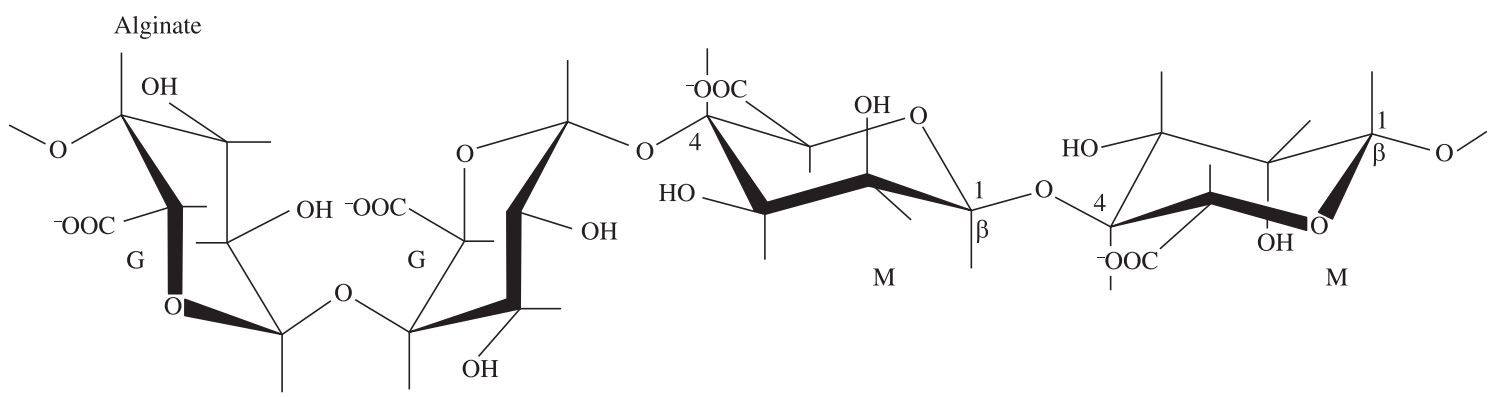

Figure 8. Structure of alginates with $\mathrm{G}$ for Guluronic acid and $\mathrm{M}$ for manuronic acid. 
The fully deacetylated product is rarely obtained due to the risks of secondary reactions and chain depolymerization. Generally, chitosans have a heterogeneous distribution of acetyl groups along the chains and the distribution is very important in controlling the solution's properties.

In addition, chitosan also occurs naturally in some fungi or in silkworm chrysalides ${ }^{[63,64]}$. Chitosan production from fungi cell walls has been known since the $70 \mathrm{~s}^{[65]}$.

Chitosan is also a semi crystalline compound and shows polymorphism depending on its physical state. It crystallizes in the orthorhombic system, like $\alpha$-chitin, and two types of chitosan can be differentiated. Chitosan $\mathrm{I}$, in salt form, with a weak degree of deacetylation, is more disordered than chitosan II, which has a high degree of deacetylation and is in the form of free amine ${ }^{[66]}$. Depending on the origin of the polymer and its treatment during extraction from raw resources, the residual crystallinity may vary considerably.

Chitosan has a pKa value of approximately $6.3^{[67]}$; at lower $\mathrm{pH}$ values, the molecule is cationic due to protonation of the amino groups. Since solubility is the chief criterion for distinguishing chitosans from parent chitin, a number of substances differing in degree and internal distribution of free amine groups are described by the term chitosan. The polymer dissolves in hydrochloric acid and organic acids such as formic, acetic, lactic and oxalic acids. Acetic acid was the most frequently used solvent of chitosan, by dissolving the biopolymer in $0,1 \mathrm{M}$ acetic acid. Previous reports have indicated that when chitosan is dissolved in saline distilled water, or

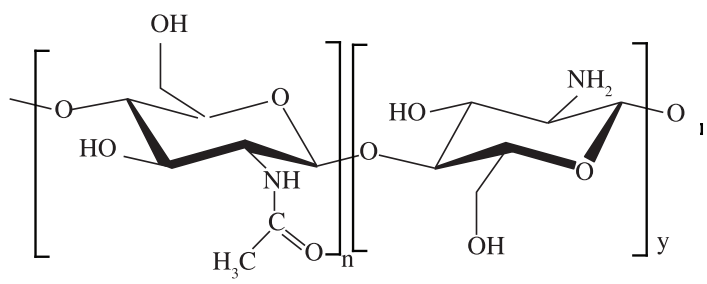

laboratory media allowing the amine protonation, it exhibits antimicrobial activity against some strains of filamentous fungi, yeasts and bacteria. Nevertheless, due to various $\mathrm{Mw}, \mathrm{DD}$, chitosan origins, etc, considerable variations in Minimal Inhibitory Concentrations (MIC) and/or minimum bactericidal concentrations of chitosan have been described. A very interesting review summarizes the chitosan MIC values according to recent data found in the literature ${ }^{[68]}$, indicating that the effectiveness of this aminopolysaccharide is dependent on microbial species. Our group has been published several papers dealing with the bioactive properties of chitosan-based matrices ${ }^{[69-72]}$ and with the bioactivity of glucosamine derivatives ${ }^{[73-75]}$.

To create a biopolymer with non-pH dependent antimicrobial activity, a non pH-dependent quaternization $^{[76]}$ can be obtained by N-Alkyl chitosan derivatives, prepared by introducing alkyl groups into the amino groups of chitosan via a Schiff's base intermediate (Figure 10). For a polymeric quaternary ammonium biocide, the hydrophilic-lipophilic balance influences antimicrobial properties by affecting the mode of interaction with the cytoplasmic membrane. Grafting alkyl chains on chitosan generally leads to biocide, which is more active against bacteria.

Chitosan-based microcapsules ${ }^{[77,78]}$ and chitosan-based films ${ }^{[79]}$ could be used as carriers for active molecules such as antioxidants. Portes et al. ${ }^{[80]}$ has elaborated environmentally friendly films exhibiting both antibacterial and antioxidative properties from chitosan and tetrahydrocurcuminoids (THCs). Two tetrahydrocurcuminoids (Figure 11), THC1 (5-hydroxy-1,7-bis(4-hydroxy-3methoxyphenyl)hept-4-en-3-one) and THC2 (5-hydroxy-1,7-bis(4-hydroxy-3,5-dimethoxyphenyl) hept-4-en-3-one), were incorporated into a chitosan film. THC1 could be prepared from natural curcumin extracted from turmeric roots (Curcuma longa L.). The resulting THCs-chitosan films had a high free-radical scavenging activity against 2,2-diphenyl-1-picrylhydrazyl in methanol. These antioxidant properties of chitosan-based

Figure 9. Structure of chitosan.

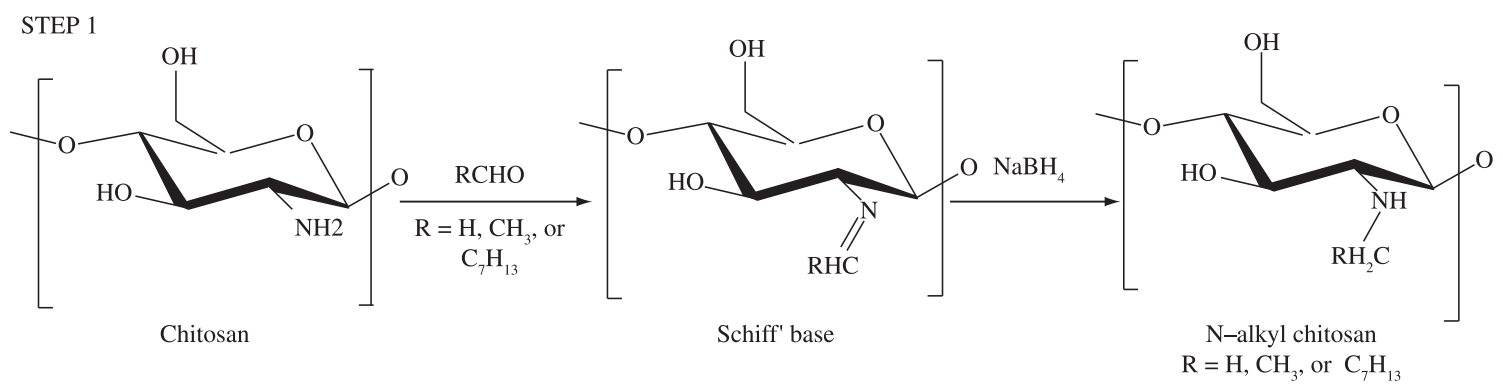

STEP 2
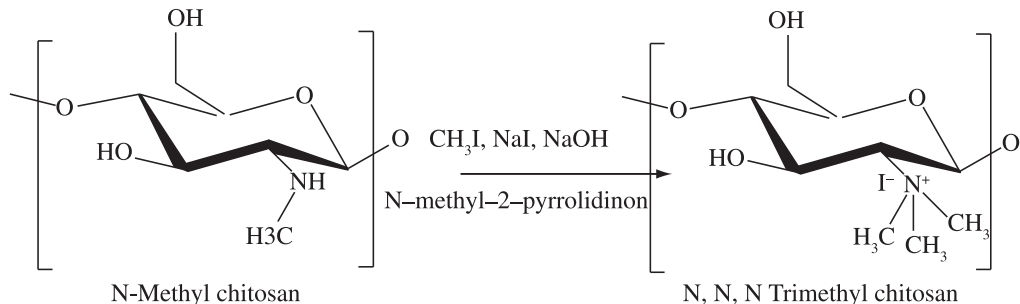

N, N, N Trimethyl chitosan

Figure 10. Shiff's base obtained from the reaction between free amino groups of chitosan and aldehydes and the synthesis of $N, N, N$-trimethylchitosan according to Belalia et al. ${ }^{[74]}$ 
<smiles>[R]Oc1cc(CCC(=O)/C=C(\O)CCc2cc([R])c(O)c(OC)c2)cc(OC)c1O</smiles>

Figure 11. THC1 and THC2 Tetrahydrocurcuminoïds studied by Portes et al. ${ }^{[78]}$

films resulted from the progressive release of THCs, due to interactions between chitosan and the antioxidative agent.

The molecular nature of these interactions was ascertained using glucosamine but the exact nature of the complex remains unelucidated. Chitosan retained its antimicrobial properties against the growth of L. monocytogenes when associated with antioxidative agents.

Moreover, in addition to its antibacterial properties and thanks to its protonated amino groups, it was shown that chitosan dissolved in an aqueous solution exhibits antioxidative properties ${ }^{[81,82]}$.

\section{Microbial origin}

\section{Bacterial cellulose and bacterial alginates}

Even if cellulose is the main component of the plant cell wall, some bacteria produce cellulose e.g. acetic acid-producing bacterium, Acetobacter xylinum. Plant cellulose and bacterial cellulose have the same chemical structure, but exhibit different physical and chemical properties.

Nguyen et al. ${ }^{[83]}$ developped a bacterially produced cellulose-film, containing nisin in order to control L. monocytogenes in foodstuff. Bacterial cellulose was produced by Gluconacetobacter xylinus K3. Nisin (2500 IU.mL ${ }^{-1}$ ) was incorporated into the cellulose matrix. Films significantly reduced $L$. monocytogenes populations on frankfurters of about $2 \log$ CFU.g ${ }^{-1}$ after 14 days of storage.

It seems that bacterial cellulose could be an alternative for plant cellulose due to a rapid production of cellulose (a few days), while trees need more than 30 years to realize full growth.

As cellulose, alginates can also be elaborated by bacterial strains such as Pseudomonas aeruginosa. The examples of applications in active packaging are the same as those identified for plant-derived polymers.

\section{Others exopolysaccharides}

As reported by Heyraud et al. ${ }^{[84]}$, bacterial polysaccharides are complex polymers leading a competitive advantage for the bacteria in relation to its environment. However, in spite of their relative abundance, there are few polysaccharides presenting original properties allowing the development of industrial applications.

During the active phase of plant growth, a significant fraction of its photosynthezised compounds (8 in 12\%) is released in the ground, essentially in the form of carbohydrates (glucose, fructose). The rhizosphere, which is the part of the ground surrounding the active roots, is the location of this root-exudation. Molecules released on the surface of roots are available for bacteria and more particularly for those which are heterotrophic for the carbon. Among these bacteria, some are able to transform these glucides into polymers, exopolysaccharides (EPS). The majority of species belong to the family of Rhizobiacea (Rhizobium, Sinorhizobium, Agrobacterium).

An example of EPS is the polysaccharide, YAS34, obtained from the strain $R$. alamii YAS34. Its chemical structure was determined and it was shown that the repetitive unit is constituted by seven sugars: one glucuronique acid, three glucoses and three galactoses. Two of the neutral sugars constitute a side chain with, at its extremity, a pyruvate group. Acetyl groups are also present, but not localized ${ }^{[82]}$. The particularity of this polysaccharide is its capacity to form physical thermoreversible gels. In salt conditions, a strongly viscoelastic behavior, sensitive to the concentration in salt is observed. Moreover, a slight gel characteristic was also obtained in strong concentration in the polymer, meaning the existence of a rigid conformation and interchain interactions.

As for glycogen, few studies based on materialderived EPS have been identified, as well as their potential as non-limited resources due to their microbial synthesis.

\section{Concluding Remarks and Future Perspectives}

It seems that bioactive packaging materials based on released bioactive compounds are more efficient than bioactive systems without any agent liberation. For non-volatile bioactive agents, the bioactivity of these categories of films is based on the diffusion of the biocide into the food. Thus, to develop these packaging systems, a better knowledge of the diffusivity of bioactive substances is needed, since few studies have been carried out on this subject. In a study related to nisin, Mauriello et al. ${ }^{[85]}$ found that the release of this active agent from the packaging was unpredictable, but temperature and $\mathrm{pH}$-dependent. Therefore, we need more research work connected with the development of appropriate models and with studies on real food products under different physico-chemical conditions.

The future development in active biopackaging materials will notably be in systems that are active only at a specific time and place, i.e. when and where required. In systems based on "release-on-command", an antimicrobial or antioxidant agent is liberated when microbial growth occurs. The basic concept is that when a change in the environment such as $\mathrm{pH}$, temperature or UV light occurs, the antimicrobial packaging responds accordingly. Therefore, the system is active only under specific conditions. This type of system is based on active compounds, which can be released at the time and place where they are needed. In the case of antimicrobial agents, the theory is that a preservative will be released from the packaging material if bacterial growth occurs, thus inhibiting growth of the emerging bacteria. This would enable a decrease in the active agent concentrations. Moreover, these new concepts can increase the shelf life 
of the active system because of a generally slower agent liberation.

\section{Acknowledgments}

The author acknowledges all published sources that she has made use of.

\section{References}

1. Kilcast, D. \& Subramaniam, P. - "Introduction", in: The stability and shelf-life of food, Kilcast D. \& Subramaniam P. (eds), Cambridge, Woodhead Publishing Ltd (2000).

2. Cutter, C. N. - Critical Reviews in Food Science and Nutrition, 42, p.151 (2002).

3. Kerry, J.P.; O’Grady, M. N. \& Hogan, S. A. - Meat Science, 74, p.113 (2006).

4. Wallace, D.; Gilder, T. V.; Shallow, S.; Fiorentino. S.; Segler, S.; Smith, K.; Shiferaw, B.; Etzel, R.; Garthright, W. \& Angulo, F. - J. Food Prot., 63, p.807 (2000).

5. Jones, J. M. - "Food safety", in: Chemical and functional properties of food components, Sikorski Z. E. (ed.), London, CRC press (2002).

6. Aymerich, M.; Garriga, J.; Jofre, A.; Martin, B. \& Monfort, J.M. - "The use of bacteriocins against meatborne pathogens", in: Advanced technologies for meat processing, Nollet, L. M. L. \& Toldra, F. (eds.), London, CRC Press (2006).

7. Mead, P. S.; Slutsker, L.; Dietz. V.; McCaig, L. F.; Bresee, J. S.; Shapiro, C.; Griffin, P. M. \& Tauxe, R. V., Emerg. Infect. Dis, 5, p.607 (1999).

8. Wolffs, P. \& Radstrom, P. - "Real-time PCR for the detection of pathogens in meat", in: Advanced technologies for meat processing, Nollet, L. M. L. \& Toldra, F. (eds), London, CRC Press (2006).

9. U.S. FOOD AND DRUG ADMINISTRATION - FDA. Center for Food Safety and Applied Nutrition. Office of Premarket Approval. GRAS Notices. http:/vm.cfsan.fda. gov. (2001).

10. Cooksey, K. - Food Additives and Contaminants, 22, p.980 (2005).

11. Coma, V. - "Antimicrobial and antioxidant biopackaging for meat and poultry", in: Meat, poultry and seafood packaging, Kerry, J. \& Whitworth, S. (eds.), Under press (2010).

12. Miltz, M.; Rydlo, T.; Mor, A. \& Polyakov, V. - Packag. Technol. Sci., 19, p.345 (2006).

13. De Jong, A. R.; Boumans, H.; Slaghek, T.; Van Veen, J.; Rijk, R. \& Van Zandvoort, M. - Food Additives and Contaminants: Part A, 25, p.975 (2005).

14. Lourdin, D. \& Colonna, P., "Les matériaux à base d'amidons et de leurs derives", in: La chimie verte, Colonna, P. (ed), Paris, Tec \& Doc (2006).

15. Arvanitoyannis, I. - J Macromo. Sci - Rev Macromo. Chem Phys, 2, p.205 (1999).

16. Petersen, K.; Nielsen, P.V.; Bertelsen, G.; Lawther, M.; Olsen, M.B.; Nilsson, N.H. \& Mortensen, G. - Trends in Food Science \& Technology, 10, p.52 (1999).

17. Tharanathan, R.N. - Trends in Food Science \& Technology, 14, p.71 (2003).
18. Coma, V. - Meat sciences, 78, p.90 (2008).

19. Coma, V. - «Perspectives for the active packaging of meat products», Advances technologies for meat processing, Nollet L. \& Toldra F. (eds.) (2006).

20. Coma, V. - "Bioactive chitosan-based substances and films" in: Current Research and Developments on Chitin and Chitosan in Biomaterial Science, v. 1, Jayakumar R. \& Prabaharan M. (eds), Research Signpost (2008).

21. Coma, V. - "Les matériaux bioactifs et biodégradables à base de chitosane" in: Chitine et Chitosane: du polymère à l'application, Crini G. (ed), Editions des Presses Universitaires de Franche-Comté, France, (2009).

22. Mathlouthi, M. - «Emballage et conservation des produits alimentaires», Mathlouthi, M. (ed), Polytechnica, Paris (1996).

23. Maynard, F. - "Edible film and method", European Patent 0935921 (1999).

24. Sebti, I. "Bio-emballage actif incorporant la nisine, diffusion de cette bactériocine en gel d'agarose", Doctorat thesis, Université Bordeaux1, France (2002).

25. Pyla, R.; Kim, T. J.; Silva, J. L. \& Jung, Y. S. - Int. J. Food. Microbiol. 137, p.154 (2010).

26. Shen, X. L.; Wu, J. M.; Chen, Y. \& Zhao, G. - Food Hydrocolloids, 4, p.285 (2009)

27. Vásconez, M. B.; Flores, S. K.; Campos, C. A.; Alvarado, J. \& Gerschenson, L. N. - Food Research International, 42, p.762 (2009).

28. Mathew, S. \& Abraham, E. - Food Hydrocolloids, 5, p.826 (2008).

29. Klemm, D.; Philipp, B.; Heinze, T.; Heinze, U. \& Wagenknecht W. "Comprehensive Cellulose Chemistry", in: Fundamentals and analytical Methods, vol.1, Klemm, D.; Philipp, B.; Heinze, T.; Heinze, U. \& Wagenknecht W. (eds.), Edition Weinheim, Wiley (1998).

30. Hjärtstam, J. \& Hjertberg, T. - Journal of Applied Polymer Science, 72, p.529 (1999).

31. De la Cruz, G. V.; Torres, J. A. \& Martín-Polo, M. O. Journal of Food Engineering, 48, p.91 (2001).

32. Cuq, B.; Aymard, C.; Cuq, J. L. \& Guilbert, S. - Journal of Food Science, 60, p.1369 (1995).

33. Coma, V.; Sebti, I. ; Deschamps, A. \& Pichavant, H.F. Journal of Food Protection, 64, p.470 (2001).

34. Sebti, I.; Pichavant, F. \& Coma V. - Journal of Agricultural and Food Chemistry, 50, p.4290 (2002).

35. Sebti, I. \& Coma, V. - Carbohydrate Polymers, 49, p.139 (2002)

36. Sebti, I.; Delves-Broughton, J. \& Coma, V. - Journal of Agricultural and Food Chemistry, 51, p.6468 (2003).

37. Sebti, I.; Blanc, D.; Carnet-Ripoche, A.; Saurel, R. \& Coma, V. - Journal of Food Engineering, 63, p.185 (2004).

38. Gemili, S.; Yemenicioglu, A, \& Altinkaya, S.A. - Journal of Food Engineering, 90, p.453 (2009).

39. Möller, H. ; Grelier, S.; Pardon, P. \& Coma, V. - Journal of Agricultural and Food Chemistry, 52, p.6585 (2004).

40. Gemili, S.; Yemenicioglu, A, \& Altinkaya, S. A. - Journal of Food Engineering. 96, p.325 (2010).

41. Aspinall, G. O. -. Advances in Carbohydrate Chemistry, 14, p.429 (1959). 
42. Chesson, A., "Supplementary enzymes to improve the utilization of pig and poultry diets", in: Recent Advances in Animal Nutrition, Haresign, W. \& Cole, D.J.A. (eds.), Butterworths, London (1987)

43. Schadel, C.; Blöchl, A.; Richter, A. \& Hoch, G. - Plant physiology and Biochemistry, 48, p.1 (2010).

44. Ebringerova, A.; Hromadkova, Z. \& Heinze; T. - Advance in polymer sciences, 186, p.1 (2005).

45. Gabrielii, I.; Gatenholm, P.; Glasser, W.G.; Jain, R.K. \& Kenne, L. - Carbohydrate Polymers, 43, p.367 (2000)

46. Hansen, N. M. L. \& Plackett D. - Biomacromolecules, 9, p.1493 (2008)

47. Hartman, J.; Albertsson, A.C.; Lindblad, M.S.; Sjoberg, J. Journal of applied polymer, 4, p.2985 (2006).

48. Gröndahl, M. \& Gatenholm P. - "Oxygen Barrier Films Based on Xylans Isolated from Biomass", in: Materials, Chemicals, and Energy from Forest Biomass, ACS Symposium Series, p.137 (2007)

49. Stipanovic, A. J.; Haghpanah, J. S.; Amidon, T. E.; Scott G. M.; Barber, V. \& Mishr, M. - "Opportunities for Hardwood Hemicellulose in Biodegradable Polymer Blends", in: Materials, Chemicals, and Energy from Forest Biomass, cap.7, ACS Symposium Series, p.107 (2007).

50. Willför, S.; Sundberg, K.; Tenkanen, M. \& Holmbom B. Carbohydrate Polymers, 72, p.197 (2008).

51. Kongruang, S. - "Quantification and reactivity of cellulose reducing ends". www.bre.orst.edu/Presentations/ SasithornKongruang.ppt.

52. Pavlath, A. E.; Voisin, A. and Robertson G. H. - "Pectinbased biodegradable water insoluble films Application of polymers in foods", in: Die Makromolekulare Chemie. Macromolecular, Symposium, Dallas TX (1999).

53. Kang; H. J.; Cheorun J. O.; YOUNG LEE, N. A.; Kwon J. H. \& BYUN M. W. - Carbohydrate polymers, 60, p.547 (2005).

54. Kang, H. J.; Job, C.; Kwon, J. H.; Kim, J. H.; Chung, H. J. \& Byun, M. W. - Food Control, 18, p.430 (2007).

55. Jin, T.; Liu, L. S.; Zhang, H. \& Hicks, K. - International Journal of Food Science and Technology, 44, p.322 (2009).

56. Choi, J. H.; Choi, W. Y.; Cha, D. S.; Chinnan, M. J.; Park, H. J.; Lee, D. S. \& Park, J. M. - LWT - Food Sciences and Technology, 38, p.417 (2005).

57. Marcos, B.; Aymerich, T.; Monfort, J. M. \& Garriga, M. - International Journal of Food Microbiology, 117, p.148 (2007).

58. Oussalah, M; Caillet, S.; Salmiéri, S.; Saucier, L. \& Lacroix, M. - Journal of Food Protection, 70, p.901 (2007).

59. Izawa, H.; Nawaji, M.; Kanako, Y. \& Kadokawa, J. I. Macromolecular bioscience, 9, p.1098 (2009).

60. Rousseau, C. F. \& Gagnieu, C. H. - Biomaterials, 23, p.1503 (2002).

61. Soares, N. D. F. F. - "Chitosan Properties and application”, in: Biodegradable polymer blends and composites from renewable resources, Long Y. (ed), Wiley, New York (2009).

62. Crini, G. \& Badot, P. M. - Progress in polymer science, 33, p.399 (2008).
63. Rungsardthong, S.; Wongvuttanakul, N.; Kongpien, N. \& Chotiwaranon, P. - Process Biochemistry, 41, p.589 (2006).

64. Paulino, A. T.; Simionato, J. L.; Garcia, J. C. \& Nozaki, J. - Carbohydrate Polymers, 64, p.98 (2006).

65. Jaworska, M. M. \& Szewczyk, K. W. - "Chitosan from Absidia sp.", in: Advances in Chitin Science, Domard A., Roberts A. F. \& Varum K. M. (eds), Jacques André Publisher, Lyon (1997).

66. Crini, G.; Guibal, E.; Morcellet, M.; Torri, G. \& Badot, P. M. - "Chitine et chitosane : synthèse, propriétés et principales application", in: Chitine et chitosane, du biopolymère à l'application, Crini, G.; Badot, P. M. \& Guibal, E. (eds.), Presse Universitaires de Franche-Comté, Besançon (2009).

67. Sudarshan, N. R.; Hoover, D. G. \& Knorr, D. - Food Biotechnol., 6, p.257 (1992).

68. Goy, R. C.; De Britto, D. \& Assis, O. B. G. - Polimeros Ciencia e Technologia, 19, p.241 (2009).

69. Coma, V.; Martial-Gros, A.; Garreau, S.; Copinet, A.; Salin, F. \& Deschamps, A. - Journal of Food Science, 67, p.1162 (2002).

70. Coma, V.; Deschamps, A. \& Martial-Gros, A. - Journal of Food Science, 68, p.2788 (2003).

71. Sebti, I.; Martial-Gros, A.; Carnet-Pantiez, A.; Grelier, S. \& Coma V. - Journal of Food Science, 70, p.100 (2005).

72. Fimbeau, S.; Grelier, S.; Copinet, A. \& Coma, V. Carbohydrate Polymers, 65, p.185 (2006).

73. Muhizi, T.; Coma, V. \& Grelier, S. - Carbohydrate Research, 343, p.2369 (2008).

74. Muhizi, T.; Grelier, S. \& Coma, V. - Journal of Agricultural and Food Chemistry, 57, p.11092 (2009).

75. Muhizi, T.; Grelier, S. \& Coma, V. - Journal of Agricultural and Food Chemistry, 57, p.8770 (2009).

76. Belalia, R.; Grelier, S.; Benaissa, M. \& Coma, V. - Journal of Agricultural and Food Chemistry, 65, p.1582 (2008).

77. Kosaraju, S. L.; D'ath, L. \& Lawrence, A. - Carbohydrate Polymers, 6, p.163 (2006).

78. Parize, A. L.; Rozone de Souza, T. C.; Costa Brighente, I. M.; Fávere, V. T.; Laranjeira, M. C. M.; Spinelli, A. \& Longo, E. - African Journal of Biotechnology, 7, p.3107 (2008).

79. Özmeric, N.; Özcan, G.; Haytac, C. M.; Alaaddinoglu, E. E.; Sargon, M. F. \& Senel, S. Journal of biomedical materials research, 51, p.500 (2000).

80. Portes, E.; Gardrat, C.; Castellan, A. \& Coma, V. Carbohydrate Polymers, 76, p.578 (2009).

81. Yen, M. T.; Yang, J. H. \& Mau, J. L. - Carbohydrate Polymers, 74, p.840 (2008).

82. Kim, K.W. \& Thomas, R.L. Food Chemistry, 101, p.308 (2007).

83. Nguyen, V. T.; Gidley, M. J. \& Dykes, G. A. - Food Microbiology, 25, p.471 (2008).

84. Heyraud, A.; Rinaudo, M.; Bresin A.; Heulin, T.; Santaella, C.; \& Baynast, R. - Bioprocédés (2008).

85. Mauriello, G.; De Luca, E.; La Storia, A.; Villani, F. \& Ercolini, D. - Letters in Applied Microbiology, 41, p.464 (2005). 